\title{
HOST PREFERENCE OF THE ECTOPARASITOID, EPYRIS QUINQUECARINATUS KIEFFER (BETHYLIDAE: HYMENOPTERA) ON CERTAIN MAIZE LEPIDOPTEROUS LARVAE \\ Abd-Elgayed, A. A. ${ }^{1}$ and S. H. A. HUSSEIN ${ }^{2}$ \\ 1- Plant Protection Department, Faculty of Agriculture, Fayoum University \\ 2- Plant Protection Research Institute, Agricultural Research Center, Giza
}

\begin{abstract}
The present study was carried out in Plant Protection Department laboratory, Fac. of Agric., Fayoum Univ. and conducted under the optimum laboratory conditions of 27 $\pm 1^{\circ} \mathrm{C}$ and $57.7 \pm 5 \%$ R.H.The parasitoid, Epyris quinquecarinatus Kieffer was reared on larvae of each of Pyroderces simplex Wlsm., Cryptoplabes gnidiella Mill., Gymnoscelis pumilata $\mathrm{Hb}$. and Sesamia cretica Led.. This bethylid parasitoid perefered larvae of $P$. simplex then $G$. pumilatta larvae, while the larvae of $C$. ginidella and $S$. cretica appeared as unsuitable hosts.

Keywords: Insect pests of maize, Biological studies, Epyris quinquecarinatus, and host preference.
\end{abstract}

\section{INTRODUCTION}

Maize (zea mays L.) is an important grain crops in Egypt, where it conforms to wheat in the economic importance. Such crop is cultivated in multiplantations thorough out along a period extending from March to October and attacked with several insect pests (Mostafa, 1981; Mostafa et al., 1986 and Davis and Pedigo, 1991)

As far as the authors are aware, no records are available in the literatures concerning biology of this bethylid parasitoid Epyris quinquecarinatus Kieffer. Only Abd-Elgayed (1995) recorded this parasitoid and its host, Pyroderces simplex Wlsm. He found the optimum conditions for rearing this parasitoid on larvae of $P$. simplex were $27 \pm 1^{\circ} \mathrm{C}$ and $57.7 \pm 5 \%$ R.H.The longest periods of oviposition (44.6 days) and adult longevity (48.8 days for female \& 15.8 days for male ) were coincided with the highest counts of egg deposition / female (129.8) and rate of deposition / $/$ / day (2.92 eggs). Also, Lanes and Azevedo (2004) recorded sixty species from Bethylidae in Florida and the same authors (2008) recorded some species belong to sub family (Epyrinae) in Denmark Azevedo and Alencar (2010) recorded Melanepyris asiaticus Kieffer in Brazil

Although conventional pesticides application has been effective for the majority of the pests, many of these toxic chemicals are expensive and may be persistent in the environment. Therefore, it was necessary to apply biological pest management using natural enemies that have been registered to be ecologically safe and risk free ( Fayad et al., 1984; El- Sherif, et al., 1987 and Abd-Ella, 1990). 
However, studies on natural enemies associated with maize insect pest in Egypt are still in lack. Therefore, the present experiment was concerned to study the following aspects: Host preference of the parasitoid, E. quinquecarinatus Kieffer on some maize insect pests under the optimum laboratory condition.

\section{MATERIALS AND METHODS}

To study the host preference of $E$. quinquecarinatus on some lepidopterous larvae for maize insect pests, its biological aspects were conducted under the optimum laboratory conditions of $27 \pm 1^{\circ} \mathrm{C}$ and $57.7 \pm 5$ $\%$ R.H. in Plant Protection Department, Fac. of Agric., Fayoum Univ. The relative humidity was maintained by using saturated solution of sodium bromide hydrated (Soliman, 1940)

\section{A. Stock culture:}

1-Hosts:

The biological aspects were experimented on four species of lepidopterous larvae as shown in Table (1).

Table (1): The hosts and larval instars were used for rearing $E$. quinquecarinatus.

\begin{tabular}{|l|c|c|}
\hline Host & Family & \multirow{2}{*}{ Instar } \\
\hline Cryptoplabes gnidiella Mill. & Pyralidae & \multirow{2}{*}{ fourth } \\
\cline { 1 - 2 } Gymnoscelis pumilata Hb. & Geometridae & \\
\cline { 1 - 2 } Pyroderces simplex Wlsm. & Cosmopterigidae & \\
\hline Sesamia cretica Led. & Noctuidae & \multirow{2}{*}{ second } \\
\hline
\end{tabular}

Mature larvae of each species were collected from the infested young plants (for $S$. cretica) or ears by using a fine hair brush. Such species were introduced in plastic cages of $15 \times 10 \times 8 \mathrm{~cm}$, provided with small pieces of young corn ear. Such cages were observed daily until the adult emergence. Pairs of newly moths (each one male + one female) were confined in chimney glasses $(9 \mathrm{~cm}$ diameter $+14 \mathrm{~cm}$ height) covered with muslin. Each cage was provided with small pieces of maize ear (as an oviposition site) and wetted cotton piece for providing humidity and adult nourishment. These cages were inspected daily for renewing the pieces of maize ears and transferred into Petri dishes $(10 \mathrm{~cm})$ as needed until pupation.

2- The parasitoid, E. quinquecarinatus

A stock culture of this parasitoid, was begun with collected immature stages associated with larvae of $P$. simplex from maize fields. Parasitized hosts were introduced in Petri dishes of $10 \mathrm{~cm}$ diameter and incubated until emergence of the parasitoid adults. Such adults were confined as couples in Petri dishes of $5 \mathrm{~cm}$ diameter, provided with corrugated filter papers and 10 host larvae in $4^{\text {th }}$ instars. These dishes were inspected daily and transfered the parasitized larvae in anther dishes and then were incubated as before. 


\section{B. Biological aspects on the hosts :}

To study the host preference of E. quinquecarinatus, 10 couples of newly emerged adults collected from the stock culture, were confined in a Petri dish of $5 \mathrm{~cm}$ diameter, provided with 4 larvae (for each host) and droplets of a $10 \%$ sugar solution for adult feeding, this unit represented one replicate. The fourth larval instar was used with, $P$. simplex, C. ginidella, and G. pumilatta while, the second instar was used with $S$. cretica. Ten replicates were used and examined daily for renewing parasitized hosts. Periods of preoviposition, oviposition, post oviposition and adult longevity were recorded in addition to deposited eggs/ female were daily counted. Parasitized larvae were transferred to another dishes then kept under the same laboratory condition in order to determine durations of the immature stages, mortality percentages and sex ratio.

\section{Statistical analysis:}

The obtained data in all previous experments were statistically analyzed by New L.S.D. and calculated the standard error for biological studies according to Senedecor and Cochran (1980).

\section{RESULTS AND DISCUSSION}

\section{A. Biological aspects:}

The pethylid parasitoid, E. quinquecarinatus was recorded as an ectoparasitod on several caterpillar pests in maize field including, $P$. simplex Wlsm., C. ginidella Mill., G. pumilatta Hb. and S. cretica Led.. However, few available reviews were recorded about the biology of this parasitoid. Therefore, the present study was initiated to evaluate its host preference on different lepidopterous larvae.

\section{Immature stages:}

Data summarized in table (2) indicated that, the incubation period of $E$. quinquecarinatus eggs not affected by hosts and ranged 12 with an average between 1.3 to 1.4 days with insignificant differences then. Percentages of hatching recorded 96.1, 95.2, 95.2, and 90.2 on; $P$. simplex, C. ginidella, G. pumilatta and S. cretica, respectively.

The larval duration showed significant differences between the hosts. Therefore, the lowest period was 3.2 days on $P$. simplex larvae but, the longest periods were 4.2, 4.1 and 4.1 days on, C. ginidella, G. pumilatta and $S$. cretica larvae respectively, . The mortalities in the parasitoid larvae increased gradually to $13.2,16.3,18.3$, and $20.2 \%$ related with $P$. simplex, G. pumilatta, C. ginidella, and S. cretica as insect hosts, respectively (Table 2).

Data represented in table (2) indicated that, the periods of pupal stage ranged $4-6$ days and averaged 4.3 days ( $P$. simplex) and 5.2 days ( $S$. cretica). The percentages of mortalities had a similar, $5.1 \%$ with $P$. simplex (lowest value) and $29.9 \%$ with S. cretica (highest value) with significant differences. 
Table (2): Durations (days) of $E$. quinquecarinatus immature stages recorded on different hosts of lepidopterous larvae.

\begin{tabular}{|c|c|c|c|c|c|}
\hline \multirow{2}{*}{ Stage } & \multicolumn{4}{|c|}{ Insect hosts } & \multirow{2}{*}{ New L.S.D. } \\
\hline & P. simplex & G. pumilatta & C. ginidella & S. cretica & \\
\hline \multirow{2}{*}{ Incubation period } & $1-2$ & $1-2$ & $1-2$ & 1.2 & \\
\hline & $1.4 \pm 0.2 \mathbf{a}$ & $1.4 \pm 0.1 \mathbf{a}$ & $1.3 \pm 0.1 \mathbf{a}$ & $1.4 \pm 0.1 \mathbf{a}$ & 0.4 \\
\hline$\%$ Mortality & 3.9 & 4.8 & 4.8 & 9.8 & \\
\hline$\%$ Hatching & 96.1 & 95.2 & 95.2 & 90.2 & \\
\hline \multirow{2}{*}{ Larval stage } & $3-4$ & $4-5$ & $4-6$ & $4-5$ & \\
\hline & $3.2 \pm 0.1 \mathrm{a}$ & $4.1 \pm 0.1 \mathbf{b}$ & $4.2 \pm 0.2 \mathbf{b}$ & $4.1 \pm 0.1 \mathrm{~b}$ & 0.5 \\
\hline$\%$ Mortality & 13.2 & 16.3 & 18.3 & 20.2 & \\
\hline \multirow[t]{2}{*}{ pupal stage } & $4-5$ & $4-6$ & $4-5$ & $4-5$ & \\
\hline & $4.3 \pm 0.2 \mathbf{a}$ & $5.2 \pm 0.1 \mathrm{c}$ & $5.0 \pm 0.1 \mathbf{b}$ & $5.2 \pm 0.2 \mathbf{c}$ & 0.2 \\
\hline$\%$ Mortality & 5.1 & 17.2 & 22.2 & 29.9 & \\
\hline \multirow{2}{*}{$\begin{array}{|ll|}\text { Total } & \text { immature } \\
\text { stages } & \end{array}$} & $8-11$ & $9-11$ & $9-12$ & $9-12$ & \\
\hline & $8.9 \pm 0.3 a$ & $10.7 \pm 0.3 \mathbf{b}$ & $10.4 \pm 0.2 \mathbf{b}$ & $11.8 \pm 0.1 \mathbf{c}$ & 0.7 \\
\hline$\%$ Mortality & 19.2 & 37.2 & 44.7 & 59.1 & \\
\hline Sex ratio $\left(+:{ }^{\wedge}\right)$ & $1: 1.5$ & $1: 1.5$ & $1: 2.3$ & $1: 2.5$ & \\
\hline
\end{tabular}

The total developmental period, averaged; 8.9, 10.4, 10.7 and 11.8 days on the larvae of P. simplex, C. ginidella, G. pumilatta and S. cretica, respectively. Also, the mortality percentages values increased gradually from $19.2 \%$ with $P$. simplex to $59.1 \%$ with $S$. cretica larvae as insect hosts.

Generally, the lowest periods of immature stages, coincided with the lowest mortality were recorded at $P$. simplex, then $G$. pumilatta and $C$. ginidell. On the other hand the highest periods and mortalities were recorded at larvae of $S$. cretica

( table, 2).

At all tested hosts, males outnumbered females. These values recorded $1: 1.5$ for $P$. simplex and G. pumilatta and (1: $2.3 \& 1: 2.5)$ in the other two hosts.

\section{Adult stage:}

As shown in table (3), at all the tested hosts, E. quinquecarinatus female passed through an obvious pre-oviposition period and averaged between $2.2-4.1$ days. On the other hand, the longest oviposition period was 41.6 days in case of $P$. simplex with significantly different about the different hosts.

Data illustrated in table (3) showed that, the adult longevity of female ranged between 40.9 and 45.7 days with insignificant differences in $P$. simplex and G. pumilatta and decreased from 18.3 to 17.1 days with $C$. ginidella and $S$. cretica, respectively.

Also, the male adult longevity showed the same trend with the different hosts and averaged between 5.1 and 14.2 days.

At all hosts, the females were survived about two weeks and laying eggs. The females that reared on larvae of $P$. simplex were survived about 7 weeks and laying an average of 113.7 eggs / female, then G. pumilatta (about 6 weeks), 81.35 eggs / female. But, female of the parasitoid were died after the 14.0 days in C. ginidella and after about 12 days only association with $S$. cretica larvae. 
Table (3): Effect of different hosts on the ovipositional periods and egg laying activity of $E$. quinquecarinatus.

\begin{tabular}{|c|c|c|c|c|c|}
\hline \multirow{2}{*}{ Duration (days) } & \multicolumn{4}{|c|}{ Insect hosts } & \multirow{2}{*}{ New L.S.D. } \\
\hline & P. simplex & G. pumilatta & C. ginidella & S. cretica & \\
\hline \multirow{2}{*}{ Pre-oviposition } & $2-4$ & $2-3$ & $3-6$ & $3-5$ & \\
\hline & $2.2 \pm 0.4 \mathrm{a}$ & $3.1 \pm 0.1 \mathbf{b}$ & $4.1 \pm 0.2 \mathrm{c}$ & $4.1 \pm 0.2 \mathrm{c}$ & 0.9 \\
\hline \multirow[b]{2}{*}{ Oviposition } & $34-49$ & $30-36$ & $13-22$ & $10-13$ & \\
\hline & $4.6 \pm 1.0 \mathrm{c}$ & $35.1 \pm 0.1 \mathrm{~b}$ & $15.3 \pm 0.8 \mathbf{a}$ & $12.2 \pm 0.1 \mathbf{a}$ & 6.5 \\
\hline \multirow{2}{*}{ Post oviposition } & $1-3$ & $1-2$ & $0-1$ & $0-1$ & \\
\hline & $1.7 \pm 0.3 \mathbf{b}$ & $1.3 \pm 0.1 \mathbf{b}$ & $0.3 \pm 0.1 \mathrm{a}$ & $0.2 \pm 0.7 \mathbf{a}$ & 0.4 \\
\hline \multirow[b]{2}{*}{ Adult longevity } & $40-53$ & $38-50$ & $17-20$ & $15-18$ & \\
\hline & $45.5 \pm 1.0 \mathrm{~b}$ & $39.5 \pm 1.0 \mathrm{~b}$ & $19.7 \pm 0.5 \mathbf{a}$ & $16.5 \pm 0.2 \mathbf{a}$ & 5.2 \\
\hline \multirow{2}{*}{ Adult longevity } & $14-21$ & $11-16$ & $5-7$ & $5-6$ & \\
\hline & $14.2 \pm 1.0 \mathbf{b}$ & $11.6 \pm 0.6 \mathbf{b}$ & $6.1 \pm 0.1 \mathrm{a}$ & $5.1 \pm 0.1 \mathrm{a}$ & 3.2 \\
\hline \multirow[b]{2}{*}{ Total eggs $/ Q+$} & 111-123 & $61-92$ & $8-23$ & $11-13$ & \\
\hline & $\begin{array}{c}113.6 \pm 2.2 \\
\text { c }\end{array}$ & $81.3 \pm 5.1$ b & $19.0 \pm 2.8 \mathbf{a}$ & $12.2 \pm 0.2$ a & 9.2 \\
\hline \multirow{2}{*}{ Eggs / q /day } & $2.2-2.9$ & $2.3-2.3$ & $0.4-1.9$ & $0.9-1.1$ & \\
\hline & $2.7 \pm 0.1 \mathrm{c}$ & $2.3 \pm 0.1 \mathbf{b}$ & $1.2 \pm 0.2 \mathbf{a}$ & $1.0 \pm 0.1 \mathrm{a}$ & 0.3 \\
\hline
\end{tabular}

As mentioned data in table (3), the bethylid parasitoid perefered larvae of $P$. simplex then $G$. pumilatta larvae, but the larvae of $C$. ginidella and $S$. cretica were unsuitable hosts for this parasitoid .

These results are agreement with Abd-Elgyed (1995), found the periods of $E$. quinquecarinatus immature stages were $1.40,3.20$, and 4.80 days for eggs, larvae and pupa, at $27 \pm 1^{\circ} \mathrm{C}$ and $57.7 \pm 5 \%$ R.H., respectevily, association with the lowest percentages of mortality and sex ratio 1: 1.50 . The respective oviposition period, female longevity, and total deposited eggs were $44.60,48.80$ days and $129.80 \mathrm{egg} /$ female, respectevily.

\section{REFERENCES}

Abd-El-Gayed, A. A. (1995). Studies on some maize insect pests and their natural enemies, M.SC. Thesis, Fayoum Fac. of Agric., Cairo Univ., pp.105-117.

Abd-Ella, M.M.H. (1990). Effect of different temperatures and hosts on certain biological aspects of Bracon brevicornis Wesm. (Hymenoptera: Braconidae), Fayoum, J. Agric. Res. \& Dev., 4(1): 89-102.

Azevedo, C.O. and Alencar, I.D.C.C. (2010). Rediscovery of Melanepyris (Hymenoptera: Bethlidae) a new synonym of Egyris, Zoologia 27(3):403-407.

Davis, P.M. and Pedigo L.P. (1991). Injury profiles and yield responses of seedling corn attacked by stalk borer (Lepidoptera: Noctuidae) J. Econ Entomol., 84(1): 294-299. 
El-Sherif, S.I.; Mostafa, F.F.; Zaki, F.N. and Saleh M.E. (1987). Biocontrol studies on corn borers in Egypt: 2-parasitism on Ostrinia nubilalis Hbn. (Pyraustidae: Lepidoptera) in maize field, Bull. Fac. of Agric., Cairo Univ., 38(2): 551-557.

Fayad, Y.H.; Amira A. Ibrahim and Lutfallah,A.f (1984). Bracon brevicornis abraconid parasite on European corn borer, Ostrinia nubilalis $\mathrm{Hbn}$., Agric., Res. Rev., 62(1):355-360.

Lanes, G.O. and Azevedo, C.O. (2008). Phylogeny and taxonomy of sclerodermini (Hymenoptera: Bethlidae: Epyrinae), Insect Systematic and Evolution, 39(1): 55-86.

Lanes, G.O. and Azevedo, C.O. (2008). Report on a collection of Bethylidae (Hymenopter) from central Florida USA, with description of a new species of lepidosternopsis Ogloblin, $J$ of Hymenopter research, 13(1):57-63.

Mostafa, F.F. (1981). Biological and ecological studies on the pink borer, Sesamia cretica Led. (Noctuidae: Lepidoptera) Ph.D. Thesis, Fac. of Agric., Cairo Univ.

Mostafa, F.F. and Kirollos, J.Y.(1986). Host preference and biological aspects of the lopper worm, Gymnoscelis pumilata Huebner (Geometridae: Lepidoptera), Fabis Newsletter,16: 29-31.

Senedecor, G.W. and Cochran, W. G.(1980). Statistical methods, $7^{\text {th }}$ Ed. 570 pp., lowa Stat., Univ. Press., Ames, lowa, USA.

Soliman, H.S.(1940). Studies on the biology of Microbracon hebetor Say. (Hymenoptera: Braconidae), Bull. Soc. Fouad $1^{\text {st }}$ ent., 24: 215-247.

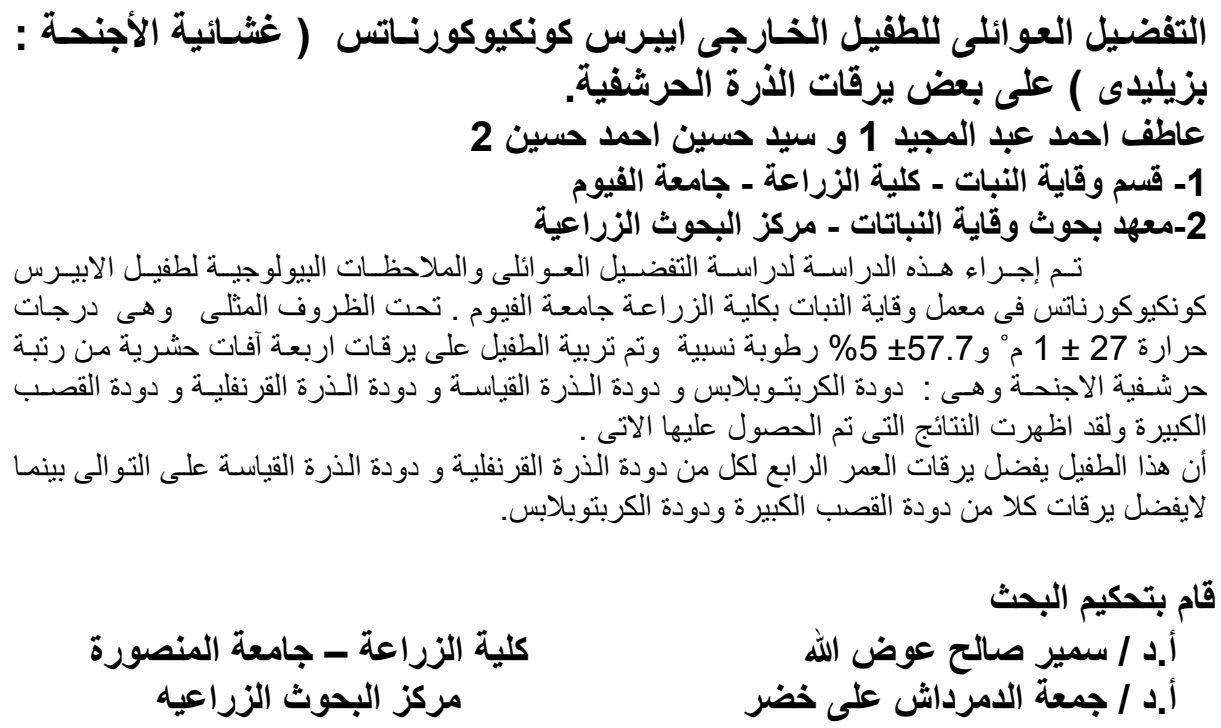

